\title{
Chapter
}

\section{SILICA AND ORMOSIL NANOPARTICLES FOR GENE DELIVERY}

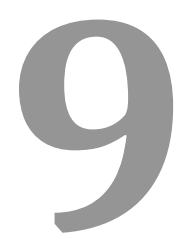

Joana C. Matos' ${ }^{1}$, Gabriel A. Monteiro ${ }^{2,3}$, and M. Clara Gonçalves ${ }^{1,4^{*}}$

${ }^{1}$ Departamento de Engenharia Química, Instituto Superior Técnico, Universidade de Lisboa, Av. Rovisco Pais, 1049-001 Lisboa, Portugal 2 Departamento de Bioengenharia, Instituto Superior Técnico, Universidade de Lisboa, Av. Rovisco Pais, 1049-001 Lisboa, Portugal ${ }^{3}$ IBB - Institute for Bioengineering and Biosciences, Instituto Superior Técnico

${ }^{4}$ Centro de Química Estrutural, Instituto Superior Técnico, Universidade de Lisboa, Av. Rovisco Pais, 1049-001 Lisboa, Portugal 


\section{Contents}

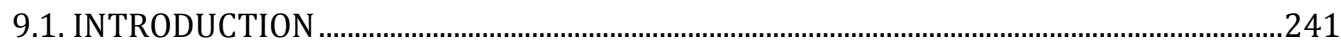

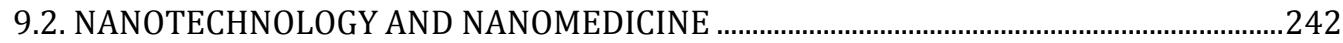

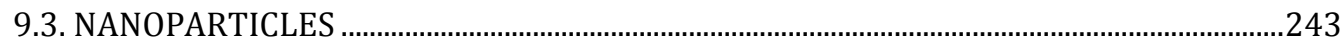

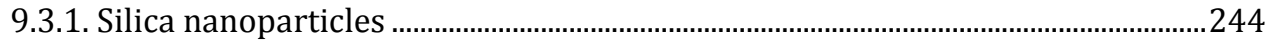

9.3.2. Silica nanoparticles synthesis and in situ functionalization synthesis

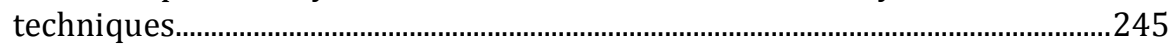

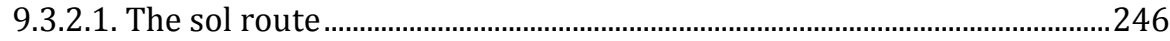

9.3.2.2. The solution route .......................................................................................24

9.3.2.3. In situ functionalization ..........................................................................252

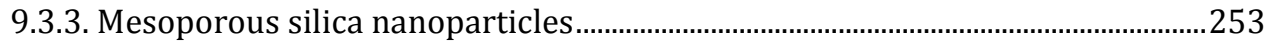

9.3.4. Hollow-sphere silica nanoparticles........................................................................25

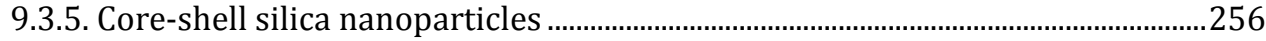

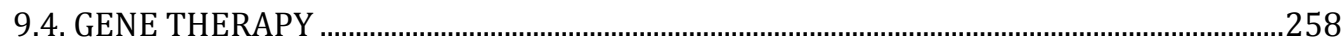

9.4.1. Silica and ORMOSIL nanoparticles for gene therapy..............................................261

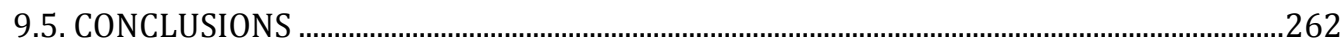

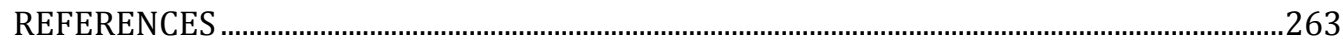




\subsection{INTRODUCTION}

Nanomedicine is an emerging area, combining nanotechnology and medicine. One of nanomedicine's main goals is the design, development and application of delivery systems for gene delivery and therapy. Selective gene transfer to cells, tissues or organs, for clinical treatment, has been discussed throughout the last half century. Recent breakthroughs in the technology required to modify genetic material brought this goal closer to a foreseeable future.

Plasmids (pDNA) are widely used in clinical and non-clinical research in gene delivery, gene therapy and DNA vaccination, however, they are quite inefficient as mediators of gene expression, as these molecules are easily degraded when administered unprotected. To overcome this difficulty, gene delivery systems have been designed and developed to efficiently carry, target and protect the plasmid DNA.

Silica and organically modified silica (ORMOSIL) nanoparticles (NPs) are promising candidates as non-viral delivery vectors. Silica presents several attractive characteristics: high biocompatibility, nontoxicity, non-immunogenicity, biodegradability, and bioconjugation ability. The silica functionalization versatility allows hybrid NPs, with tunable hydrophilic/hydrophobic surface character, high cargo capacity, and a prolonged period of blood circulation, making them even more interesting as gene carriers.

This chapter is a brief introduction to the topic of nanomaterials/NPs and their significance in nanomedicine, followed by a description of the bottom-up sol-gel method of NPs synthesis.

The main concepts of gene therapy will also be addressed. The advantages and disadvantages of different methods will be discussed, with emphasis on the use of synthetic NPs to improve the gene delivery efficiency of non-viral vectors. 


\subsection{NANOTECHNOLOGY AND NANOMEDICINE}

Nanotechnology involves the manipulation of matter on a nanometric scale, with the aim of developing new functional material or systems, whose structures exhibit novel and/or improved properties. Due to their size, the materials developed often have very specific physical, chemical and/or biological properties. The nano prefix refers to the multiplication of a given unit by $10^{-9}$. In the international units system (SI), a nanometre denotes one billionth of a metre, corresponding approximately to the length of 10 hydrogen atoms or 5 silicon atoms aligned.

Nanoscale materials may be classified in terms of the number of dimensions not confined to the nanometric scale. Nanoparticles are considered zero dimensional (0D) (zero dimensions not confined to the nanometric scale); nanotubes, nanofilaments and nanofibres extend across one dimension (1D); nanofilms and nanocoatings can be characterised by a width and a length, while height is negligible, and may be regarded as two dimensional (2D) nanomaterials; finally, bulky materials, such as photonic crystals or metamaterials, are classified as three dimensional (3D). Considering the inherent nanoscale functional components of living cells, it was inevitable that nanotechnology would meet biotechnology, giving rise to nanobiotechnology.

Nanobiotechnology is a new and important field of research due to the many applications in areas such as drug discovery and delivery, and pharmaceutical manufacturing. These classes of applications are often included under the term nanopharmaceuticals.

Nanomedicine is a closely related field, resulting from the application of nanotechnology to medicine. There is an increasing optimism about its applications, where significant advances in the diagnosis and treatment of diseases are expected. In the last decade, a deep understanding of the molecular processes underlying mechanisms of disease has been realised. This knowledge changed some of the paradigms of clinical diagnosis methods, supported by detection and monitoring at the molecular level, such as cells, DNA, messenger RNA (mRNA), peptides and proteins. Furthermore, as targets exist on a nanoscale, probes with equivalent size have been developed allowing the integration of nanotechnology and biology/medicine, responding to the increasing demand for gene profiling, and high-throughput drug and disease screening without complex instrumentation or processing steps [1]. Drug delivery and gene therapy become one of the most promising applications of nanomedicine, by making use of NPs as carriers [2]. Figure 1 illustrates the relationship between nanobiotechnology and nanomedicine. 


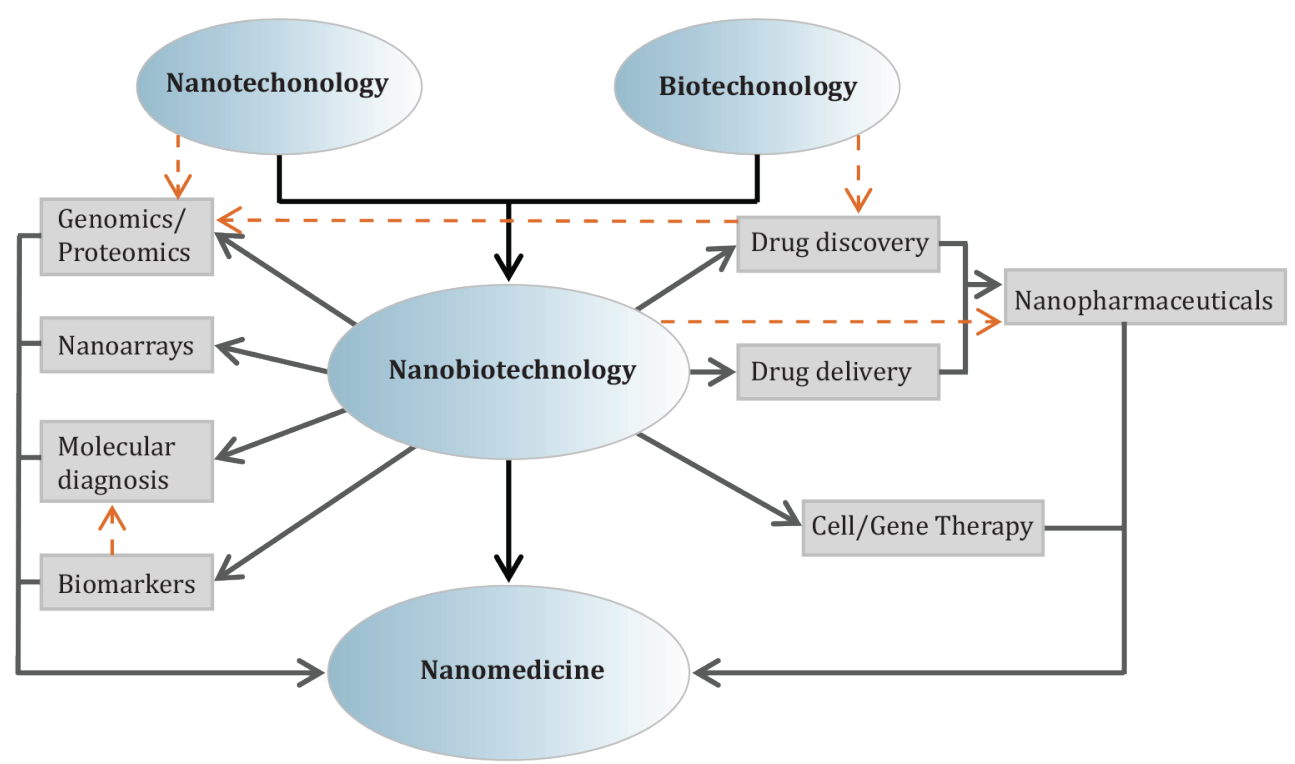

Figure 1. Nanobiotechnology and nanomedicine relationship (adapted from [2])

\subsection{NANOPARTICLES}

Due to a wide range of attractive characteristics, NPs are of high significance in material science research, to both the academic and industrial communities.

In addition to their outstanding surface-to-volume ratio, NPs possess unique thermal, mechanic, electrochemical, catalytic, optical, electronic and magnetic properties, depending on their size, shape and composition. Instead of changing the NPs composition, one may play with the size and/or shape, to fine tune a desired property or set of properties.

NPs may exhibit a wide range of geometries - from spherical to tubular, through centric, eccentric and star like - may be plain or nanostructured core-shell or porous structure - exhibit different sizes and shell thicknesses, may be hollow, may differ in crystallinity and surface morphology, and finally may be fine-tuned relative to one or more properties.

NPs can be functionalized and eventually bioconjugated with a wide range of small ligands and/or large biomolecules. NPs enable the encapsulation and controlled release of various substances (e.g. drugs, biomolecules, cosmetics, and dyes), and may play a singular role in certain biomedical devices.

Finally, NPs can be capable of accomplishing multiple objectives such as imaging and therapy (theranostics), or performing a single advanced function through the incorporation of multiple functional units [3]. For biomedical 
applications, an appropriate size range $(\sim 10-200 \mathrm{~nm})$ and a monosized distribution are normally required for effective operation.

Due to the nanoscale associated with these materials, classical physics are often unable to explain their properties, which are easier to understand in the domain of quantum mechanics. While the use of quantum mechanics enables many interesting hypothesis, it also increases the degree of difficulty in the complete understanding of nanomaterials.

\subsubsection{Silica nanoparticles}

NPs may comprise material of biological origin, such as phospholipids, lipids, lactic acid, dextran, chitosan, or have inorganic characteristics, such as polymeric, carbonic, silica- or metallic-based materials [4].

Silica is the most abundant mineral on the Earth's crust, and over time it was naturally introduced to human life and later to engineering. It is most commonly found in nature as sand or quartz, as well as in the cell walls of diatoms [5]. With chemistry very similar to $\mathrm{C}$, Si plays a central role in inorganic natural materials. The structural unit of silica is a tetrahedron (with $\mathrm{sp}^{3}$ hybridization), whose base and sides have a triangular shape with an oxygen atom at each vertex and a silicon atom at the centre $\left(\mathrm{SiO}_{4}\right)^{-4}$. These tetrahedral units are interconnected by sharing their vertices, which may occur regularly or randomly. In the first case the 3D organisational diversity leads to different polymorphic forms of silica (quartz or tridymite for example). Occasionally an aperiodic 3D network forms, leading to glass formation. Silica NPs may be crystalline or amorphous.

$\mathrm{SiO}_{2} \mathrm{NPs}$ present several advantages over organic polymers. During the $\mathrm{SiO}_{2}$ NPs synthesis, they may be easily separated by centrifugation; they are more hydrophilic, making the re-suspension of NPs easier, and not subject to microbial attack. Recently, different fluorescent $\mathrm{SiO}_{2} \mathrm{NPs}$ have emerged as a particularly fascinating fluorescent probe which has aroused great interest in biology and medicine $[1,6]$. Highly luminescent $\mathrm{SiO}_{2} \mathrm{NPs}$ have been prepared for the selective targeting of a wide range of important cells, organs or tissues (in particular when diseased, with cancer, specific infectious, etc.) and they have demonstrated advantages in terms of multiplexing capabilities, ease of functionalization and also greater sensitivity and photostability.

Magnetic silica NPs, as an example, can be used for separation and targeting techniques of trace amounts of bioanalytes in biological complex matrices. Their magnetic properties can also be linked to the fluorescence, making multifunctional silica NPs, which can be useful for imaging cells, tissues and other organs as well as for the delivery of therapeutic agents to specific targets. These silica NPs are of great interest from a technological point of view, especially for the diagnosis and treatment of diseases in nanomedicine. 
$\mathrm{SiO}_{2} \mathrm{NPs}$ have shown great versatility due to chemical and/or physical surface modification, which may increase their biocompatibility. Extensive studies about $\mathrm{SiO}_{2}$ NPs biodistribution $[7,8]$ and toxicology $[3,9,10]$ have shown that these NPs are well tolerated and in some cases biodegradable or excreted after performing their function.

$\mathrm{SiO}_{2}$ NPs present high and controllable mechanical and chemical stability. Their porosity can also be easily modulated in terms of the pore size and structure [11].

Due to a wide range of advantages, $\mathrm{SiO}_{2} \mathrm{NPs}$ are considered to be of great promise in nanomedicine [11], specifically in drug delivery systems and gene therapy. In drug delivery systems, drug molecules are loaded into $\mathrm{SiO}_{2} \mathrm{NPs}$, where surfaces have been previously changed by the introduction of biorecognition entities, allowing the delivery system to target specific cells or receptors in the body [12]. In gene therapy, in a pursuit of more efficient DNA delivery vectors for both basic research and clinical trials, ultrafine $\mathrm{SiO}_{2} \mathrm{NPs}$ functionalized with amino groups, can bind efficiently to pDNA, protecting it from enzymatic attack while still transfecting in vitro cells $[13,14]$.

\subsubsection{Silica nanoparticles synthesis and in situ functionalization synthesis techniques}

Several methods to accurately produce silica NPs with a narrow distribution of sizes, controlled shapes and morphology, surface chemistry, porosity, and homogeneity, have been developed. Most use the bottom-up approach of sol-gel methodology.

The sol-gel process has many advantages, which led to its use even before the underlying scientific principles were understood. These advantages include a lower processing temperature (close to room temperature), allowing minimal thermal degradation and low energy processing costs, high homogeneity, directly obtained in solution on a molecular scale, and a high purity which depends only on the precursor's purity. Furthermore, sol-gel methodology may be used in any basic laboratory (no sophisticated equipment or class room conditions are needed).

The sol-gel chemistry comprises chemical reactions involving colloidal particles in a sol, or between alkoxide-precursors and water, in a solution, leading to a highly porous amorphous gel product, where a liquid phase (solvent, catalyst and eventually excess reactants) may be retained. 0D, 1D, 2D, or 3D products can be produced, depending on the experimental conditions. Figure 2 illustrates the sol-gel versatility. 


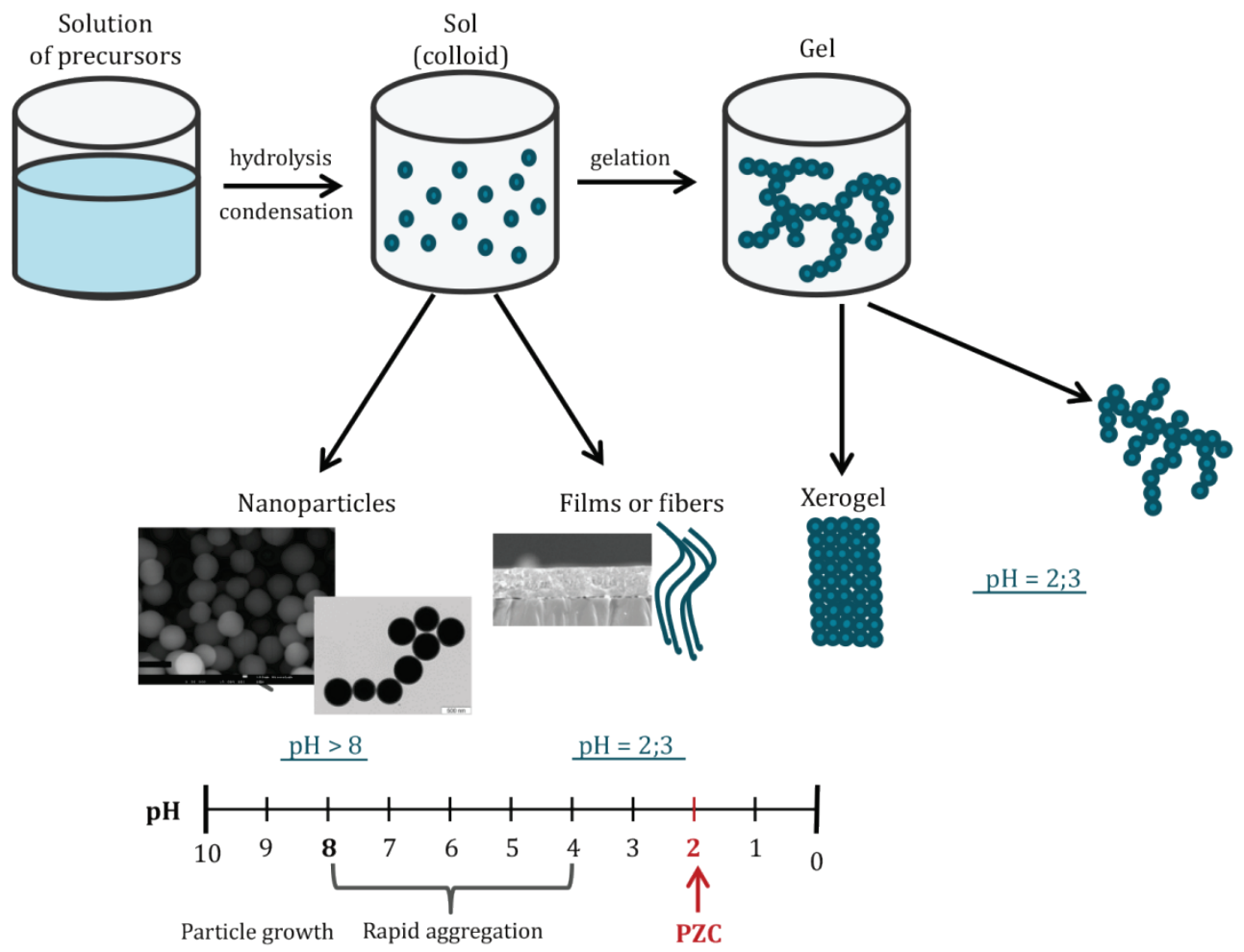

Figure 2. Sol-gel versatility

\subsubsection{The sol route}

In the sol route, colloidal particles are formed in an aqueous medium from ionic species, following colloidal chemistry principles. In the case of silica, for example, diluted silicic acid sols, containing $\sim 1 \mathrm{~nm}$ sized NPs, will undergo rapid growth to $2-4 \mathrm{~nm}$, at $\mathrm{pH} 2-3$. Above $\mathrm{pH} \mathrm{7,} \mathrm{silica} \mathrm{solubility} \mathrm{increases,}$ enhancing NPs growth, which can reach up to 4-6 $4 \mathrm{~m}$, by coalescence and Ostwald ripening (Figure 3).

Sodium silicate solution is another sol starter for the synthesis of $\mathrm{SiO}_{2} \mathrm{NPs}$. Here, monomers, dimers, trimers, etc. will hydrolyse to form the amorphous Si-O-Si network. 


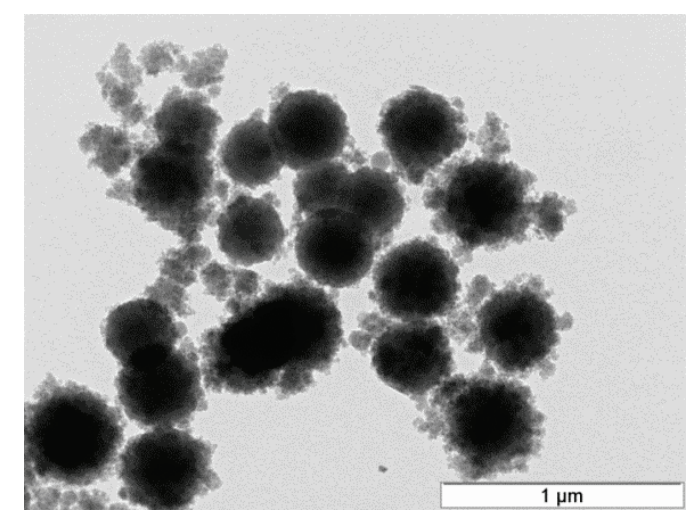

Figure 3. Transmission electron microscopy (TEM) images evidencing Ostwald ripening in $\mathrm{SiO}_{2}$ functionalized NPs

\subsubsection{The solution route}

The solution route is the most common synthesis process. Here metallic salts, metal alkoxides, or other organometallic precursors undergo hydrolysis and condensation to form a wide range of sol-gel products. Because of the hydrophobic nature of the alkyl groups, organometallic precursors and water are not miscible and the addition of a common solvent (usually an alcohol) becomes necessary to promote miscibility between reactants.

The pH plays a critical role in all sol-gel processes (Figure 2). At low pH, particularly below 3 (the isoelectric point of silica is 2), complete hydrolysis produces linear or highly branched polymeric species giving rise to 3D structures, with nanopore diameters $<2 \mathrm{~nm}$. As the $\mathrm{pH}$ increases towards 7 , dissolution and condensation reactions take place and the gel structure coarsens to some extent. Above $\mathrm{pH} 7$, there is maximum NPs growth, due to an increase in silica solubility, promoting depolymerisation of siloxane bonds, and producing the monomeric silica necessary for the aging process (Ostwald ripening coarsening mechanism, Figure 3).

In sol-gel methodology, NPs synthesis is always performed under basic catalysed conditions. Water dissociates immediately at $\mathrm{pH}$ over 7 , and a hydrolysis reaction take place by hydroxyl attack to the silicon atom, according to Equation 1:

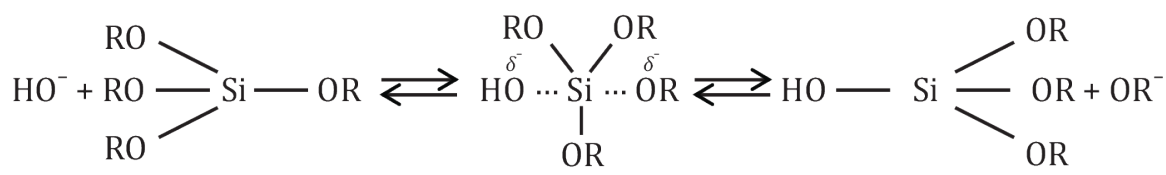


Then, a second nucleophilic attack allows the formation of the Si-O-Si network, according to Equation 2:

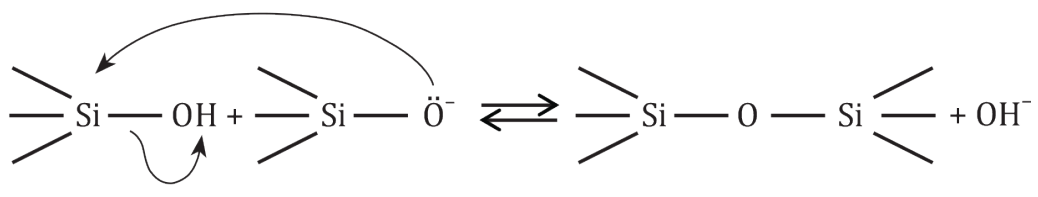

Hydrolysis and condensation occur simultaneously rather than sequentially; the initial condensation is quite fast, although it slows down as polymerization progresses.

The $\mathrm{SiO}_{2}$ NPs solution route comprises two common via: the microemulsion process (or reverse emulsion) and the classical Stöber method.

In the first process a reverse-micelle or water-in-oil (w/o) microemulsion system is formed by adding water, oil and surfactant. The hydrolysis and condensation reactions will take place in confined nanoreaction vessels, formed by the dispersed aqueous phase in the continuous oil matrix.

The nucleation and growth kinetics of silica are highly regulated in the size and size distribution of water droplets in the microemulsion system. In the last few years, several dye-doped $\mathrm{SiO}_{2} \mathrm{NPs}$ have been synthesised via the w/o microemulsion technique. In this case, to increase the electrostatic attraction of the dye molecules to the negatively charged silica matrix, polar dye molecules are used to ensure successfully encapsulation into $\mathrm{SiO}_{2} \mathrm{NPs}$ [11].

The classical Stöber method was introduced in 1968, by Stöber and co-workers, and allows the synthesis of fairly monodisperse $\mathrm{SiO}_{2} \mathrm{NPs}$, with diameters between $50 \mathrm{~nm}$ and $2 \mu \mathrm{m}$ [15]. The Stöber method has been extensively investigated and optimised in order to synthesise dye-doped $\mathrm{SiO}_{2}$ NPs by covalent bonded to organic fluorescent dye molecules $[11,16,17]$. Through the procedure described by Stöber, an alkoxide precursor such as tetraethyl orthosilicate (TEOS) is hydrolysed in an ethanol mixture, under basic catalysis. The hydrolysis and condensation reactions take place in a plain reactional vessel, allowing the formation of silica NPs.

The Stöber method allows an eco-friendly synthesis of NPs, does not use surfactants, and the synthesis reactions occur at room temperature [16].

Arkhireeva and Hay [17] obtained sub-200 nm NPs by slightly modifying the Stöber method. However, synthesised $\mathrm{SiO}_{2} \mathrm{NPs}$ (in sub- $100 \mathrm{~nm}$ size range) present high polydispersity and irregular shape [18-20], and therefore, in order to obtain monosized and nanoscale particles, the classical Stöber method is slightly modified [16]. 
In the methods described above, the concentration of the reactants (TEOS and water), the EtOH to water ratio, and $\mathrm{pH}$, strongly affects the NPs size, size distribution and morphology. This feature is also affected by the nature of the surfactant, the molar ratios of water to surfactant, in the microemulsion process.

NPs prepared through the microemulsion method exhibit smooth surfaces and low polydispersity. Through the Stöber method, NPs smaller than $100 \mathrm{~nm}$ radius present less monodispersity, may lose spherical shape and present rough surfaces. For use in biomedicine, however, the microemulsion method is not as safe as the Stöber method. The use of surfactants in the NPs synthesis carries a higher risk of cytotoxicity. A procedure based on the Stöber method is described by Gonçalves and co-workers [21] (Figure 4 illustrates the flowchart).

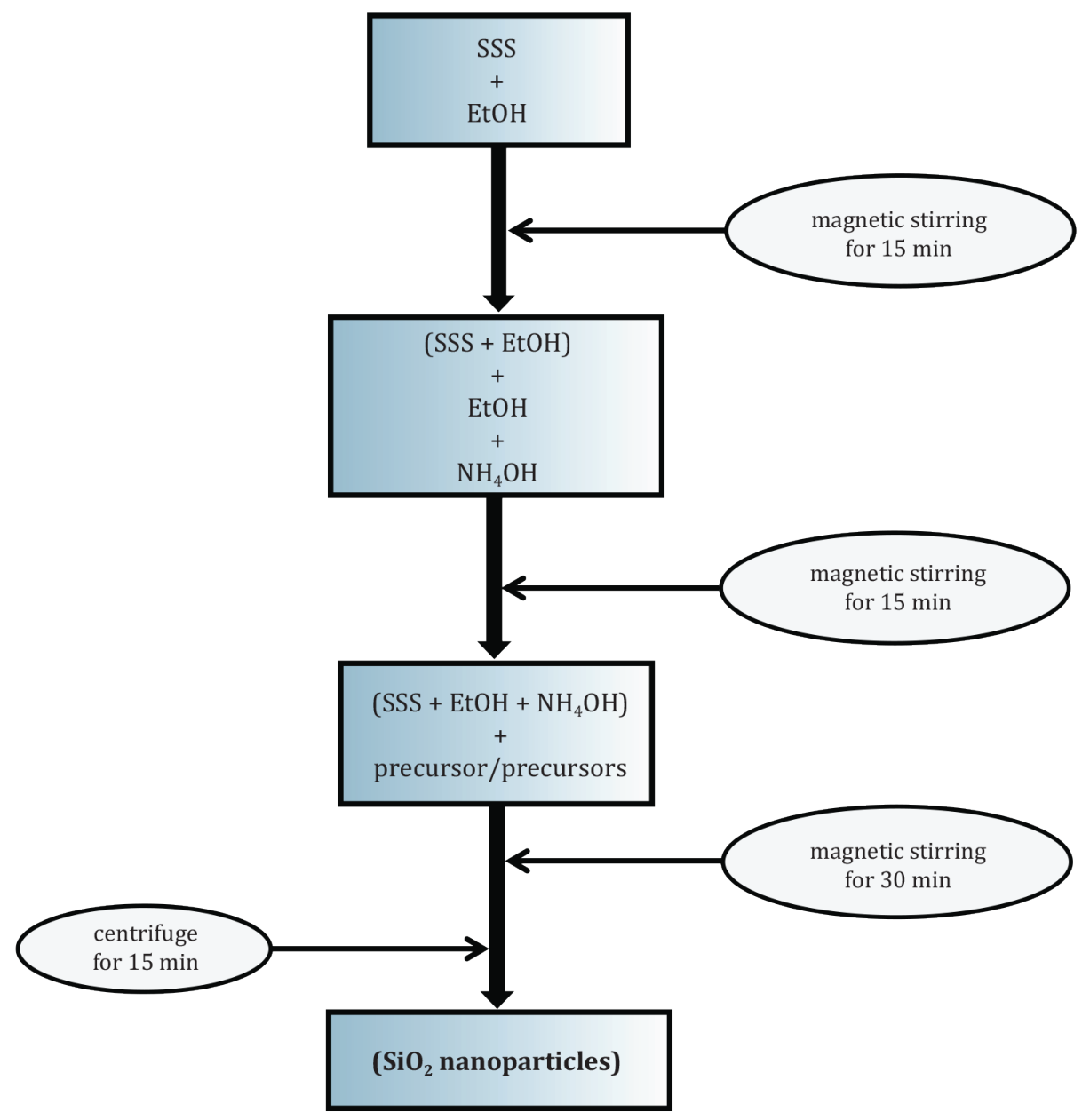

Figure 4. Stöber sol-gel method flowchart for the synthesis of $\mathrm{SiO}_{2} \mathrm{NPs}$ 
In the Stöber method aqueous sodium silicate solution is used as a nucleating agent (Solution 1), and is added to the reaction vessel prior to the silica precursors. Sequentially, aqueous sodium silicate solution $\left(2.2 \mathrm{wt} \% \mathrm{SiO}_{2}\right)$ is homogenised and re-suspended in water through ultrasonication, for $15 \mathrm{~min}$. An aliquot of Solution 1 is diluted in ethanol, under magnetic stirring (15 min.), then, a mixture of ethanol (co-solvent) and ammonia solution (catalyser) is added and magnetically stirred, for an extra $15 \mathrm{~min}$. In a second step, the silica precursors are added drop by drop to Solution 2, under vigorous stirring. A sol forms and it will be stirred for half an hour before centrifuge and washing, with ethanol and bi-distilled water. Spherical, monosized, smooth surface silica NPs are obtained (Figure 5).

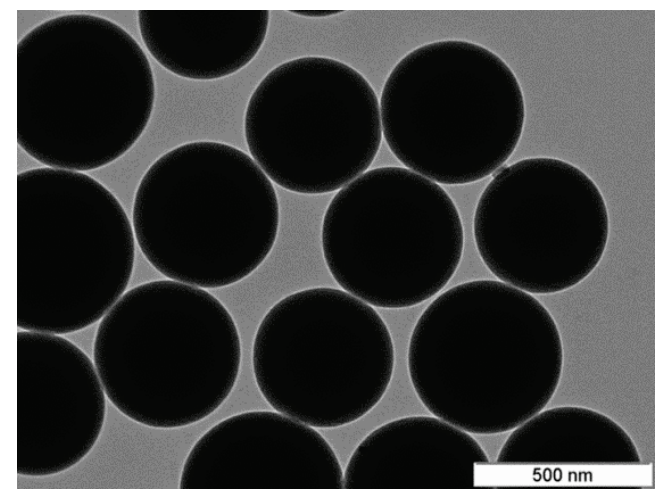

Figure 5. TEM images of $\mathrm{SiO}_{2} \mathrm{NPs}$ synthesised through the Stöber method

Based on the classical 2D model described by LaMer et al. [22], which was used as a model for qualitative interpretation in monodisperse NPs synthesis, Huang et al. [23] proposed a procedure to produce monodisperse spherical $\mathrm{SiO}_{2} \mathrm{NPs}$ with sizes ranging between $30-100 \mathrm{~nm}$. The strategy is based on an effective selection of reaction conditions for the Stöber method, and relies on a modification of the conceptual classical LaMer model of nucleation and particle growth.

Based on these principles, Gonçalves and co-workers used the procedure shown in Figure 6 to obtain monodisperse $\mathrm{SiO}_{2}$ NPs. 


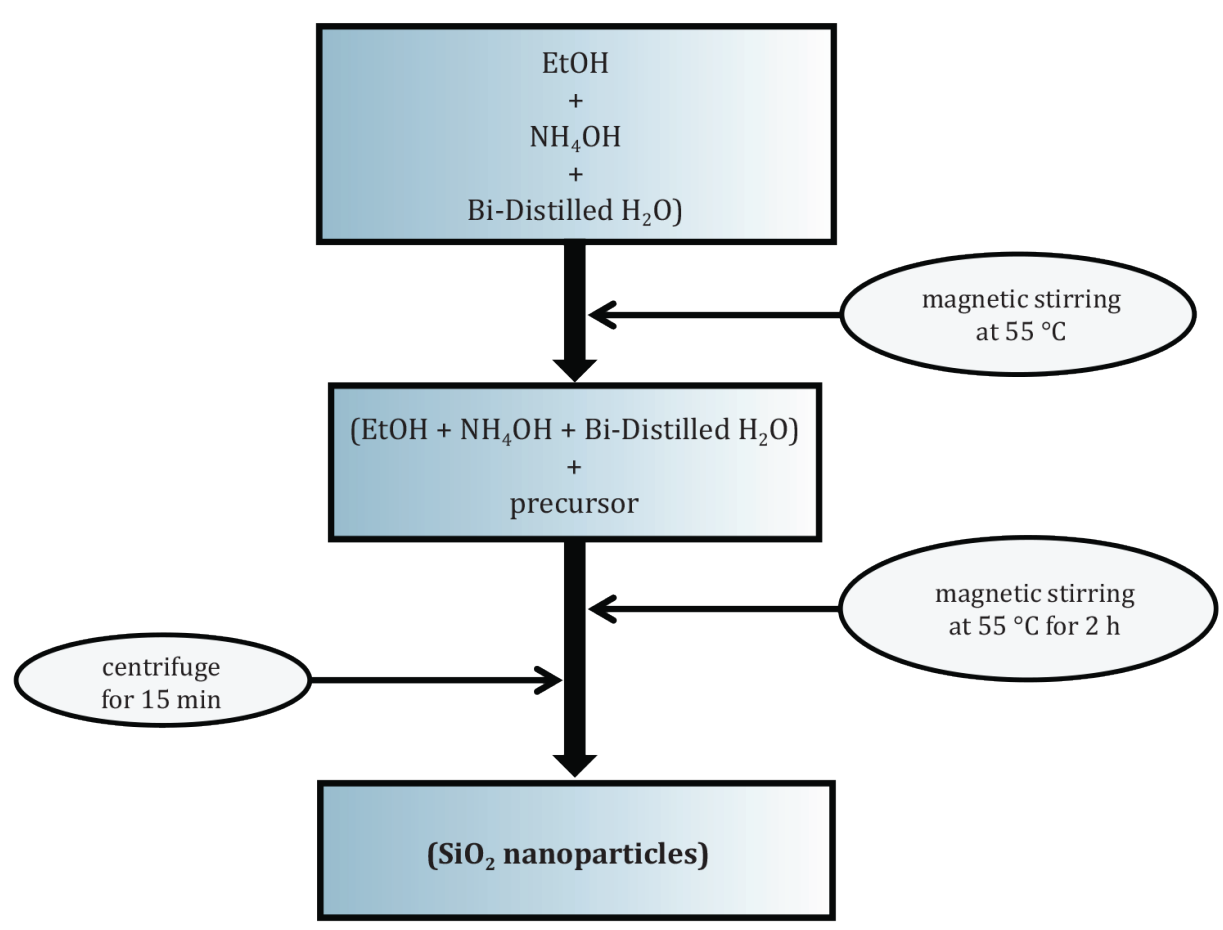

Figure 6. LaMer method flowchart for the synthesis of $\mathrm{SiO}_{2} \mathrm{NPs}$

In the LaMer procedure no nucleating agent is used. A first solution of ethanol, ammonia and bi-distilled water is formed and heated to $55^{\circ} \mathrm{C}$, under vigorous magnetic stirring. After temperature stabilisation, the silica precursors are injected quickly (into the solution), and left under magnetic stirring for two hours. A sol forms and silica NPs will be separated from the reactional bath through centrifugation. The LaMer procedure allows the synthesis of uniform, monosized, smooth surface, silica NPs under $100 \mathrm{~nm}$ (Figure 7).
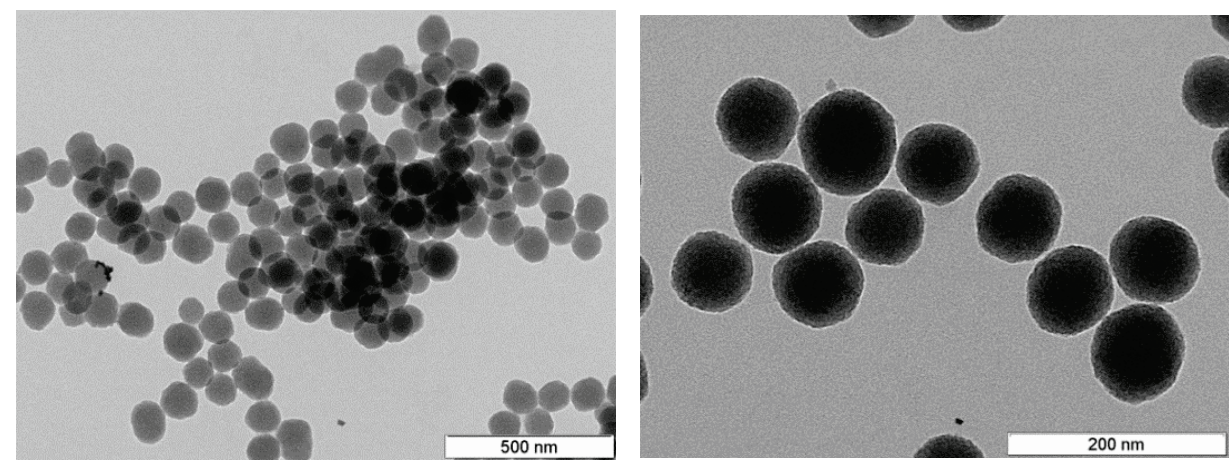

Figure 7. TEM images of silica NPs synthesised by the LaMer method 


\subsubsection{In situ functionalization}

Several attempts have been made to modify the NPs surface chemistry incorporating a variety of functional (usually organic) groups within the inorganic silica matrix (functionalization). This is important for applications such as gene therapy, since the NPs functionalization will increase their biocompatibility, improve the pDNA resistance to enzymatic action and allow a more efficient cellular internalization. [16,24]. The sol-gel route has great potential for in situ functionalization. The miscibility of alkoxide and functionalized silane compounds allows a complete polymerisation of all the precursors, yielding highly homogeneous hybrid products. Nonetheless, the specific precursor's hydrolysis rates may cause inhomogeneities or even phase separation at nanoscale. A sequential addition process, in which the least reactive precursor is pre-hydrolysed to some extent before more reactive is added, or the presence of complexing chelating agents, aimed at retarding the hydrolysis kinetics of the most reactive precursor, allow the organic functional group to be placed randomly along the silica chain. More than one functionalized silane compound can be introduced in the sol-gel synthesis process, offering multiple functionalities to the same synthesised NPs. Figure 8 shows TEM images of in situ amine- and 3-glycidoxypropyltrimethoxysilane (GPTMS) - functionalized $\mathrm{SiO}_{2}$ NPs, along with the respective Fourier transform infrared spectroscopy (FTIR) spectra, where amine and GPTMS finger prints are highlighted (Figure 9).

(a)

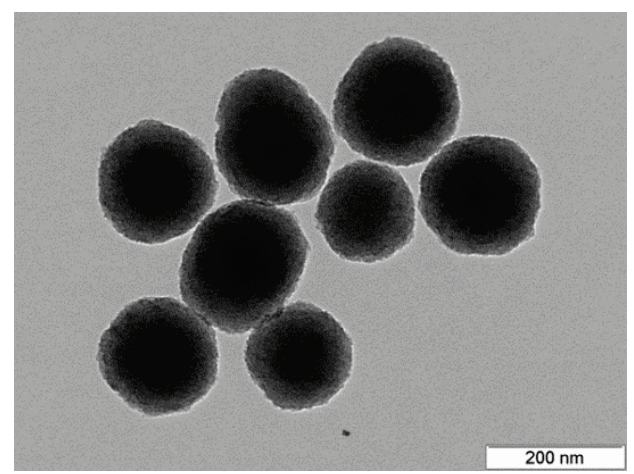

(b)

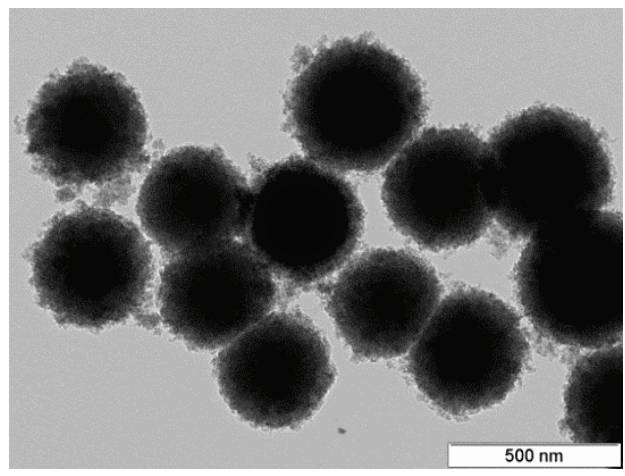

Figure 8. TEM images of in situ amine-functionalized silica NPs (a) and GPTMS functionalized $\mathrm{SiO}_{2} \mathrm{NPs}(\mathrm{b})$ 


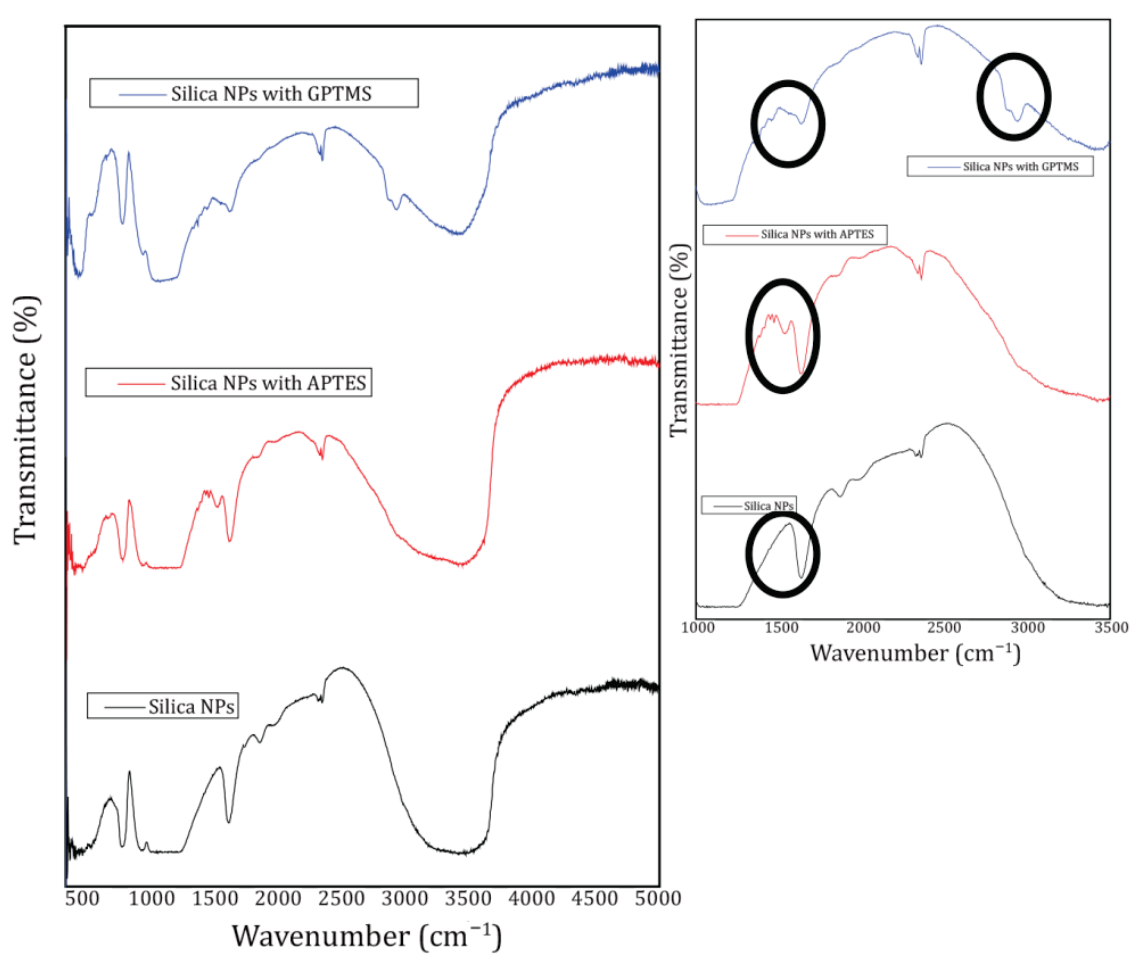

Figure 9. FTIR spectra of inorganic and functionalized $\mathrm{SiO}_{2} \mathrm{NPs}$, where functional groups finger prints are highlighted

\subsubsection{Mesoporous silica nanoparticles}

Mesoporous $\mathrm{SiO}_{2}$ NPs present a very large surface area with controllable pore size, volume and architecture. This characteristic acts as an important advantage when NPs loading is the main purpose.

The synthesis of mesoporous silica NPs is done by modifying the Stöber method, adding surfactants that behave like templates, and will later be chemically or thermally removed [25-27] (Figure 10). Pores size of 10 and $300 \AA$ have been reported along with different porous structured nanophases, using a replica of the surfactant template (Figure 11). During the synthesis of mesoporous $\mathrm{SiO}_{2} \mathrm{NPs}$, fine synthetic control will result in high surface areas with well controlled particle sizes and shapes that render these NPs very interesting [25-29]. 

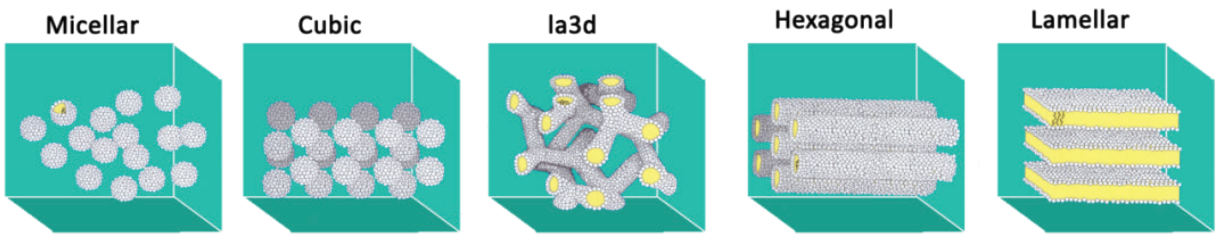

Structure transfer from surfactant aggregates to $\mathrm{SiO}_{2}$ nanoparticles

Figure 10. Surfactant as template in nanostructured mesoporous silica NPs

(a)

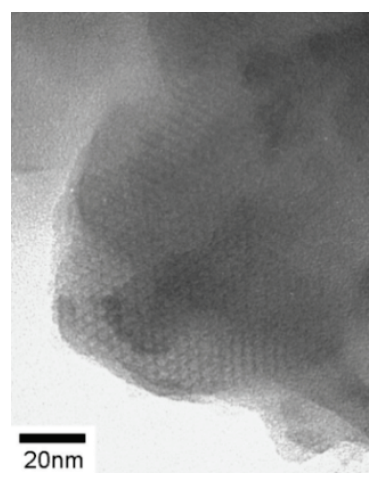

(b)

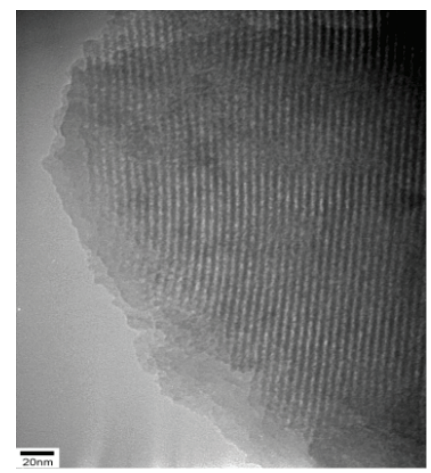

(c)

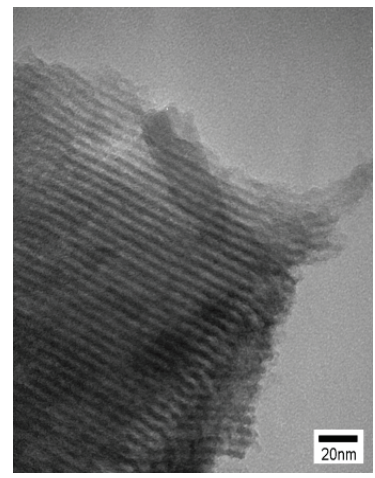

Figure 11. TEM images of nanostructured mesoporous silica NPs: (a) cubic domain,

(b) biphasic I1+HI, (c) $L a$

\subsubsection{Hollow-sphere silica nanoparticles}

Hollow-sphere NPs can be created through the condensation of alkoxysilanes (or mixtures of alkoxysilanes and functionalized silanes) onto polymer-based templates, metal organic frameworks or other nanomaterials. Later the template will be removed by chemical etching or thermal degradation (Figure 12). 


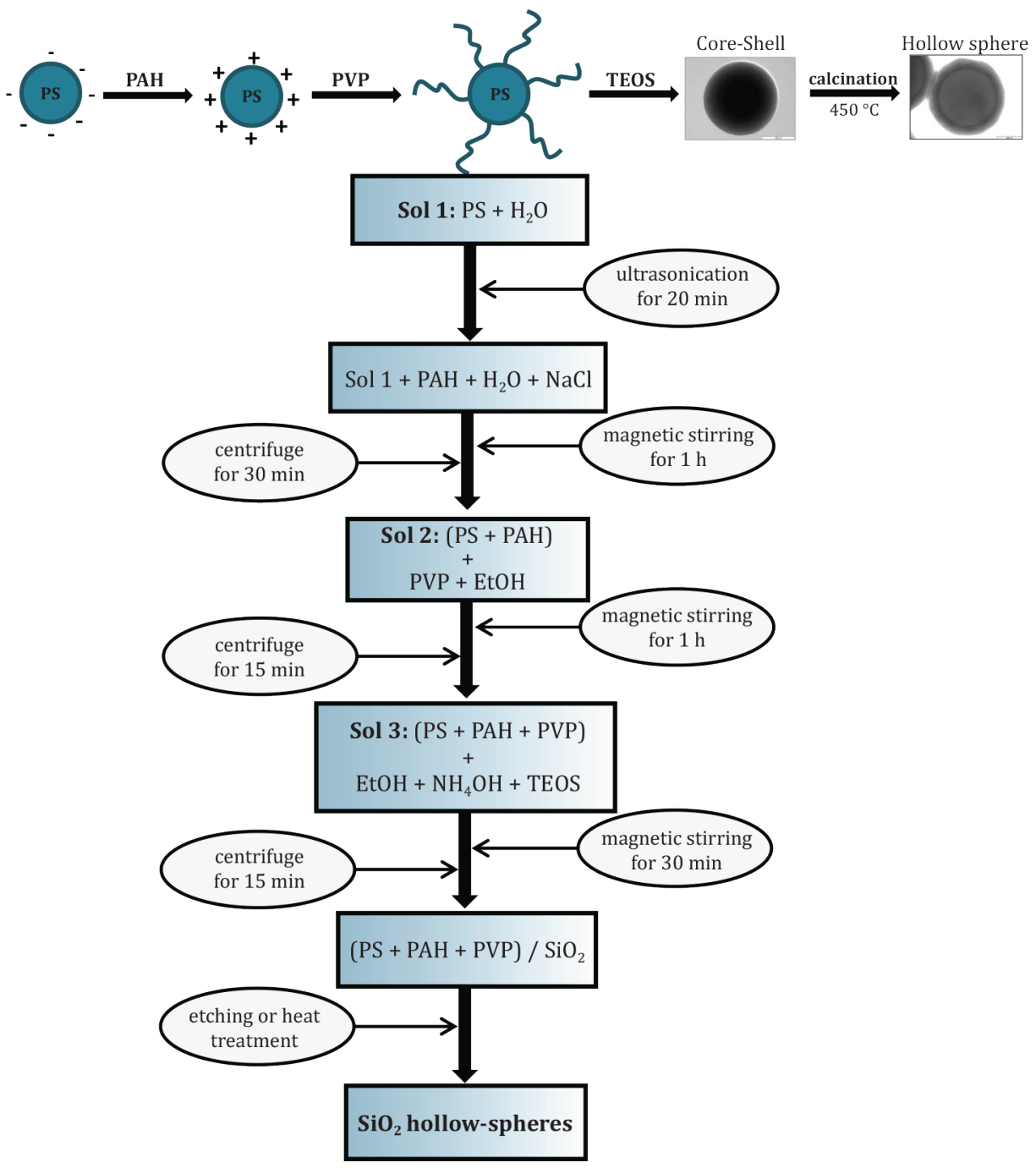

Figure 12. Scheme of hollow-sphere synthesis

Hollow-sphere NPs are capable of carrying large amounts of payload or filling their cores with other desirable materials such as polymers, gold or silver [30-35] along with the gene delivery performance. Figure 13 shows TEM images of hollow $\mathrm{SiO}_{2} \mathrm{NPs}$ and illustrates the FTIR of all stages of the synthesis process. 


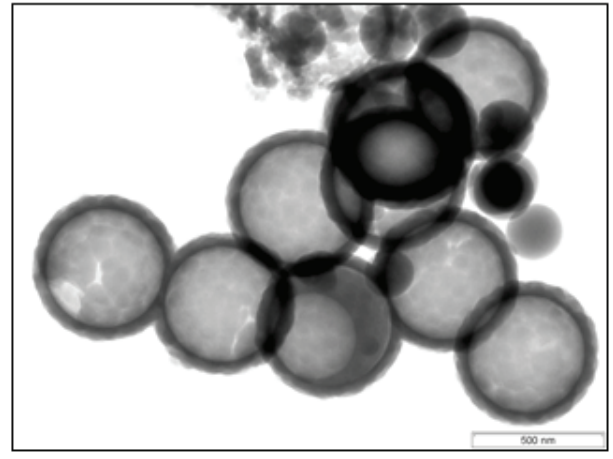

(a)

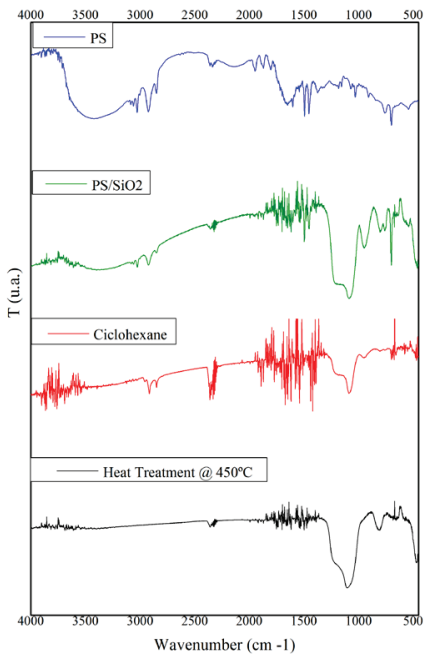

(b)

Figure 13. Hollow $\mathrm{SiO}_{2}$ NPs: (a) TEM image, (b) FTIR of NPs in all stages of the synthesis process

\subsubsection{Core-shell silica nanoparticles}

Another possible architecture is core-shell structure. Here a great diversity of materials can also be used as the core template or shell structure. Gonçalves and co-workers described the synthesis of ORMOSIL core-shell NPs for biomedical purposes [36]. They used two different materials as core - iron oxide and $\mathrm{SiO}_{2}$ - and amino-, methyl-, vinyl- and phenyl-functionalized ORMOSIL as shell.

Core-shell NPs have great potential in the future of biomedical applications, since these NPs constitute a scaffold to create multi-functional NPs, applicable to several fields; theranosis (therapeutics and diagnostics) [36] and gene delivery performance are some of the possibilities.

Figure 14 illustrate TEM images of iron oxide $(\sim 6 \mathrm{~nm}$ diameter $)$ used as core, its isothermal hysteresis behaviour and the final core-shell nanoarchitecture with multiple iron oxide particles in the core and ORMOSIL shell. 


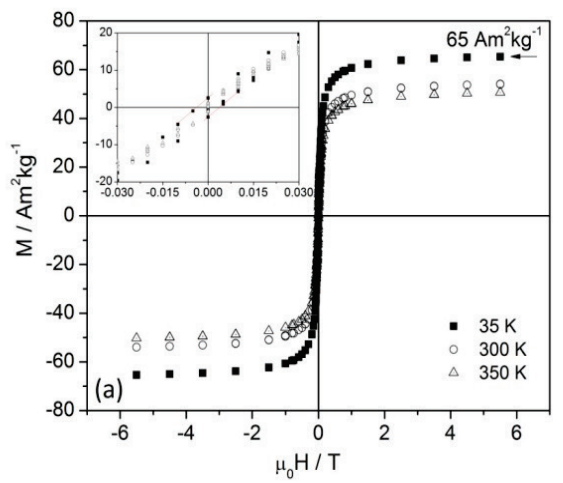

(a)

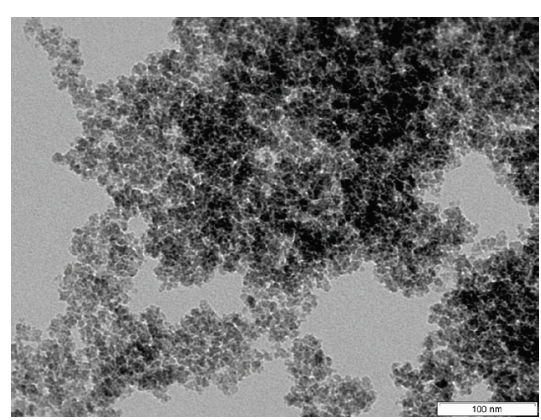

(b)

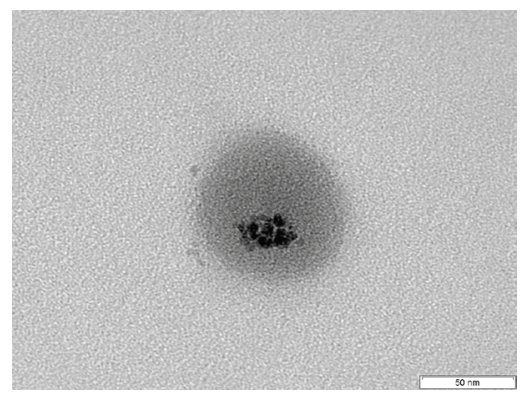

(c)

Figure 14. Core-shell NPs: (a) $\mathrm{Fe}_{2} \mathrm{O}_{3}$ isothermal hysteresis behaviour; (b) TEM images of $\mathrm{Fe}_{2} \mathrm{O}_{3}$ core; and (c) core-shell NPs

This core-shell nanoarchitecture proved to be an interesting contrast agent for magnetic resonance imaging (MRI), as illustrated in Figure 15, where a MRI image of non-contrasted (blank) zebrafish and MRI image of contrasted zebrafish with iron oxide-coke ORMOSIL-shell NPs are shown. 


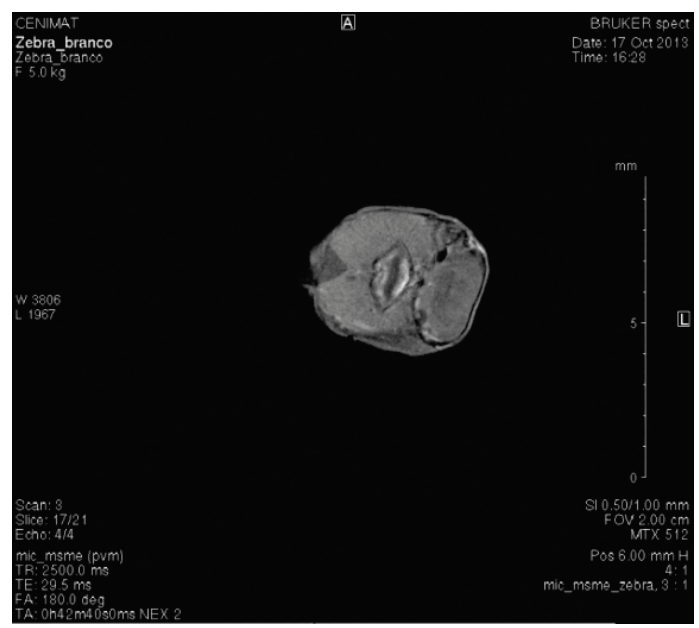

(a)

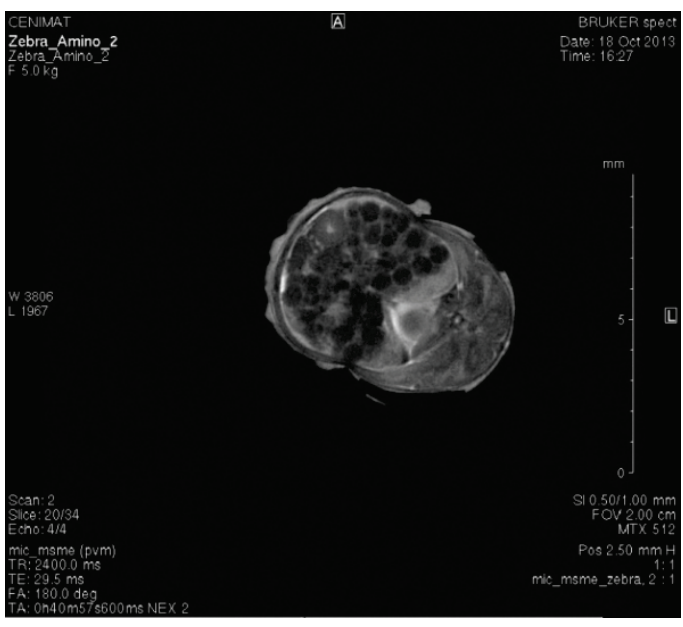

(b)

Figure 15. MRI image of non-contrasted (blank) zebrafish (a) and MRI image of contrasted zebrafish with core-shell NPs (b)

\subsection{GENE THERAPY}

Gene therapy is based on a process, conceptually simple and attractive, which consists of the transfer of one or more functional genes into a cell, tissue or organ (in vivo, in situ or ex vivo) for the treatment of genetic or acquired diseases (infections, cancer and degenerative diseases among others). 
The first gene therapy clinical trial took place in the early 1970s, where DNA and RNA of the tumour viruses were successfully delivered as genetic information to the genomes of mammalian cells [37]. Despite many failures throughout history, in 2006 confidence in gene therapy increased when a melanoma treatment using a retroviral formulation was successful [37]. In early 2015, approximately 2100 clinical trials had been conducted or had been approved, the majority based on viral vectors for gene delivery [38].

Over recent decades, new methods aimed at the delivery of genes to mammalian cells have been developed, focussing attention on gene therapy and DNA vaccination. The success of gene therapy is strongly dependent on the efficacy of the transfection processes, that is, the ability of DNA to reach the nucleus of the target cell in sufficient amounts to be effective; able to properly express the gene of interest. It is thus necessary to identify the target cell types and the appropriate DNA sequences in order to use and adopt suitable methods to reach these objectives. Efficient transportation of the therapeutic gene(s) to the nucleus of the target cells can then be carried out by either viral or non-viral vectors. Examples of viral vectors include the modified retrovirus and adenovirus, and are generally more efficient than the non-viral vectors, however, these viral systems raise several safety concerns which are absent in non-viral systems such as plasmids. Plasmids have great potential as safe vectors, can be produced on large scale with high reproducibility, and low costs, and may be stored at room temperature [39]. Plasmid systems have the potential to provide nucleic acid-based therapeutic where the products should have the ability to be easily and repeatedly administrated to patients with a reduced immune response, making them similar to the traditional pharmaceuticals. Non-viral methods typically produce low levels of transfection and expression of the gene, however, when compared with viral methods. Nevertheless, some recent developments in vector technology have yielded molecules and techniques with efficiencies that approach those of viruses [40].

The injection of naked DNA is the easiest method of non-viral transfection although is many times inefficient. The main physical methods used to enhance gene delivery are electroporation and the gene gun or particle bombardment. The electroporation method consists of short high voltage pulses that create transient pores in the plasma membranes allowing DNA entrance into cells. In the gene gun method, DNA is coated onto gold NPs and loaded into a particle delivery system which generates a force to achieve penetration of the DNA into the cells.

Non-viral gene carriers normally include organic polymers and liposomes $[41,42]$. The former have more potential for gene delivery, as they are easily prepared and present a reduced risk of immune response. Lipoplexes (lipid nucleic acid complexes), cationic polymers and solid lipid NPs, have shown promise as a delivery vector in gene therapy [43-45], however, cationic molecule-based systems present low gene transfer efficacy and toxicity 
associated with inflammation. Several attempts have been made to decrease the cytotoxicity of cationic non-viral systems [46], however, an ideal method with high transfection efficiency and relatively safety in vitro and in vivo has not yet been found. Inorganic NPs with high biocompatibility, lack of toxicity and stable chemical and physical properties, are promising as gene carriers [47]. Roy et al. [48] used $\mathrm{SiO}_{2}$ NPs as gene carriers in pDNA transfection studies. Since then several attempts have been made to develop procedures for modifying the carrier surface (functionalization procedures), in order to increase their biocompatibility and resistance to enzymatic action and internalization efficiency $[16,24]$.

The NPs should be stable enough to interact with the cell membrane while still allowing the release of the DNA from the complex. The size of the nanocarrier is an important parameter for consideration. Some processes will influence the diameter of the NPs/complexes and their net charge stability - sonication, filtration and dialysis are some of the examples. The nanometre or colloidal size ranges, around the $10-1000 \mathrm{~nm}$, are an important feature, since their sub-micron size (and also sub-cellular size) allows deep penetration into the tissues by fine capillaries, being normally taken up efficiently by the cells.

Notwithstanding, NPs are metastable materials, with a huge tendency to agglomerate or growth. Prior to any complexation to genetic material NPs need to be stabilised. Another practical problem involves NPs suspension's kinetic stability which may be achieved through the use of buffer solutions, $\mathrm{pH}$, and temperature control, or by steric hindrance.

There are several physiological barriers that must be overcome to achieve the desired gene expression. For efficient gene delivery and transfection, internalisation must take place without disruption of the gene intended to be expressed. Internalisation through the cell membrane must occur, followed by endosomal escape, going through the cytoplasm until entering the nucleus. Bottlenecks may be formed during this process, however, which will limit the transfection efficiency. The internalisation mechanisms are also largely dependent on the cell type, the vector used and the physical-chemical parameters of the complex determined by the synthesis or production process. Another physiological constraint that can influence the expressed protein levels is the nucleases role in pDNA degradation after administration and during the traffic to the cell nucleus $[48,49]$. It has been shown that the majority of pDNA administrated in animal models is degraded by a population of exo/endonucleases that are constitutively present in plasma and cytosol of the receptor cells $[50,51]$. The use of vectors that encapsulate the DNA is thus essential to avoid its degradation. 


\subsubsection{Silica and ORMOSIL nanoparticles for gene therapy}

Inorganic NPs such as those made of silica are a promising solution for gene delivery systems, since they present some of the desired characteristics such as biocompatibility, lack of toxicity and stability as already described [47]. Several studies have been successful in using silica NPs as a system for gene delivery [52,53]. Several efforts have also been made to modify the surface of various polymer vectors in order to improve their biocompatibility, increasing their circulation time, internalisation efficiency and improving the link to the genes. A common functionalization procedure uses silane compounds with terminal functional groups that will interact electrostatically or covalently with the molecule to be delivered. One common chemical used for in situ surface functionalization of polymeric and silica NPs is the (3-aminopropyl) triethoxysilane (APTES). The amino group will electrostatically interact with proteins, enhancing their adsorption [54-56]. Studies carried out recently have shown that, among the commonly used alkoxide precursors, APTES is the one promoting plasmid DNA interactions more efficiently $[16,52,57,58]$. It has been shown that $\mathrm{SiO}_{2} \mathrm{NPs}$, functionalized with amino groups, bind and protect pDNA from enzymatic digestion allowing cell transfection in vitro $[13,14,21,59]$. APTES can also dissolve in both polar and non-polar solvents, and has high solubility in cell membranes [60,61].

Gonçalves and co-workers have shown that amino ORMOSIL NPs efficiently bind to the pDNA forming complexes that have been successful internalized by Chinese hamster ovary cells [21]. $\mathrm{SiO}_{2}$ NPs functionalized with APTES are promising candidates for use as carriers in gene therapy.

Figure 16 shows the high efficiency in pDNA complexation of $\mathrm{NH}_{2}$-ORMOSIL NPs, by the common agarose gel electrophoresis, and the internalization in both Chinese hamster ovary cells and zebrafish larvae. 


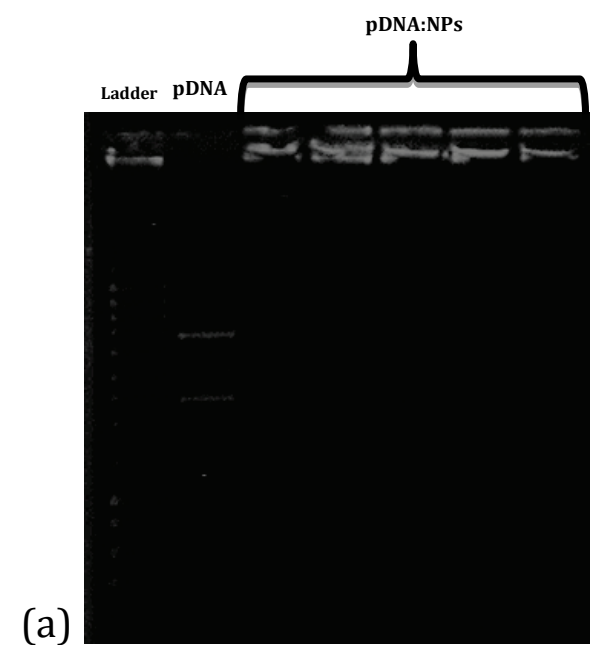

(b)

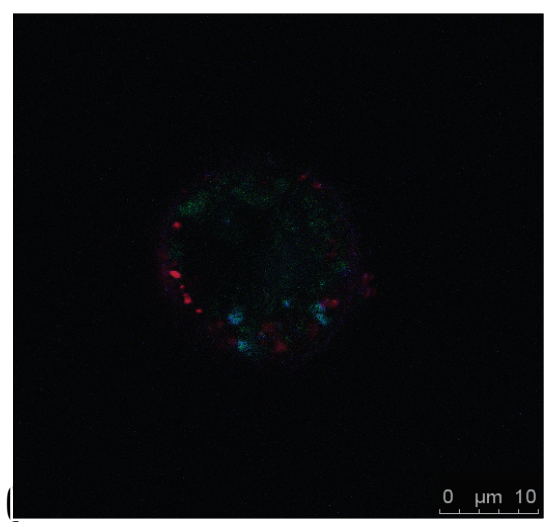

c)

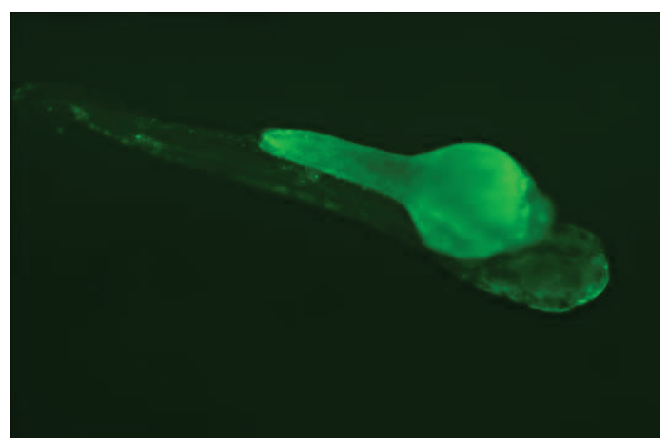

Figure 16. pDNA and ORMOSIL NPs agarose gel electrophoresis (a); fluorescence-labelled ORMOSIL NPs internalised and transfected by Chinese hamster ovary cells (b); fluorescence-labelled ORMOSIL NPs internalised by zebrafish larvae (c)

\subsection{CONCLUSIONS}

Over recent decades a large number of viral and non-viral systems for gene delivery have been developed and studied. Both types present advantages but also still have drawbacks. Gene delivery through viral-based systems present long-term expression, effectiveness and expression of the therapeutic genes, with a high transfection rate, however, they also have some limiting disadvantages: immunogenicity, toxicity, the risk associated with virus handling and limitations on the production of large batches. The non-viral methods are supported by higher biosafety, simpler techniques, and can effectively target cells and tissues, however, their biggest disadvantage for clinical use is their low transfection efficiency. 
Silica and ORMOSIL NPs are considered a good scaffold for multi-functional biomedical applications. They present a large surface area which could allow them to be loaded with one or more types of drugs to be used in drug delivery, or even by a fluorophore, for real time imaging and diagnosis. Through surface functionalization with specific groups, $\mathrm{SiO}_{2} \mathrm{NPs}$ can be conjugated with several types of biomolecules, such as specific linkers, fluorescent labels, antibodies or DNA, giving them simultaneous therapeutic and diagnostic (theranosis) capabilities. Many studies have shown that $\mathrm{SiO}_{2}$ NPs or ORMOSIL NPs are promising candidates for use as non-viral carriers in gene therapy. These NPs have many unique properties, such as a high biocompatibility, nontoxicity and good potential to control their size, shape and cargo. It has also already been shown that these NPs bind efficiently to plasmid DNA and are able to protect it from enzymatic degradation. These are all promising characteristics for non-viral vectors, which are likely to be used in gene therapy.

\section{REFERENCES}

1. L. Wang, W. Zhao, W. Tan. Nano Research 1 (2008) 99-115.

2. K.K. Jain, The Handbook of Nanomedicine, Humana Press Basel, Switzerland, 2008.

3. J. Lu, M. Liong, Z. Li, J.I. Zink, F. Tamanoi. Small 6(16) (2010) 1794-1805.

4. W.H. D. Jong, P.J. Borm. Int. J. Nanomedicine 3 (2008) 133-149.

5. D. Luo, W.M. Saltzman. Gene Therapy 13 (2005) 585-586.

6. W. Tan, K. Wang, X. He, X.J. Zhao, T. Drake, L. Wang, R.P. Bagwe. Med. Res. Rev. 24 (2004) 621-638.

7. P. Decuzzi, B. Godin, T. Tanaka, S.-Y. Lee, C. Chiappini, X. Liu, M. Ferrari. J. Control. Release 141 (2010) 320-327.

8. T. Yu, D. Hubbard, A. Ray, H. Ghandehari. J. Control. Release 163 (2012) 46-54.

9. T. Liu, L. Li, X. Teng, X. Huang, H. Liu, D. Chen, J. Ren, J. He, F. Tang. Biomaterials 32 (2011) 1657-1668.

10. Y.-S Lin, C.L. Haynes. Chem.Mater. 21 (2009) 3979-3986.

11. L. Wang, K. Wang, S. Santra, X. Zhao, L.R. Hilliard, J.E. Smith, Y. Wu, W. Tan. Anal. Chem. 78 (2006) 647-654.

12. C. Barbé, J. Bartlett, L.G. Kong, K. Finnie, H.Q. Lin, M. Larkin, S. Calleja, A. Bush, G. Calleja, C. Barbe. Adv. Mater. 16 (2004) 1959-1966.

13. C. Kneuer, M. Sameti, E.G. Haltner, T. Schiestel, H. Schirra, H. Schmidt, C.-M. Lehr. Int. J. Pharm. 196 (2000) 257-261.

14. X.-X. He, K. Wang, W. Tan, B. Liu, X. Lin, C. He, D. Li, S. Huang, J. Li. J. Am. Chem. Soc. 125 (2003) 7168-7169.

15. W. Stöber, A. Fink. J. Colloid Interface Sci. 69 (1968) 62-69.

16. R. Colaço, M.C. Gonçalves, L. Fortes, L.M.D. Gonçalves, A.J. Almeida, B.F.Martins. Curr. Nanosci. 9 (2013) 168-172.

17. A. Arkhireeva, J.N. Hay. J. Mater. Chem. 13 (2003) 3122-3127.

18. Z. Lei, Y. Xiao, L. Dang, M. Lu, W. You. Micropor. Mesopor. Mat. 96 (2006) 127-134.

19. H. Giesche. J. Eur. Ceram. Soc. 14 (1994) 189-204.

20. R. Lindberg, J. Sjöblom, G. Sundholm. Colloids Surf. A 99 (1995) 79-88. 
21. J.C. Matos, Design and Production of Silica and ORMOSIL Nanoparticles for Gene Delivery, Lisbon, Portugal, 2014.

22. V.K. LaMer, R.H. Dinegar. J. Am. Chem. Soc. 72 (1950) 4847-4848.

23. Y. Huang, J.E. Pemberton. Colloids Surf. A 360 (2010) 175-183.

24. G. Storm, M.T. Kate, P.K. Working, I.A. Bakker-Woudenberg. Clin. Cancer Res. 4 (1998) 111-115.

25. Q. Cai, W.Y. Lin, F.S. Xiao, W.Q. Pang, X.H. Chen, B.S. Zou. Micropor. Mesopor. Mater. 32 (1999) 1-15.

26. D.R. Radu, C.-Y. Lai, J. Huang, X. Shu, V.S.Y. Lin. Chem. Commun. (2005) 1264-1266.

27. T. Yokoi, H. Yoshitake, T. Tatsumi. J. Mater. Chem. 14 (2004) 951-957.

28. S. Jambhrunkar, M. Yu, J. Yang, J. Zhang, A. Shrotri, L. Endo-Munoz, J. Moreau, G. Lu, C. Yu. J. Am. Chem. Soc. 135 (2013) 8444-8447.

29. B.G. Trewyn, C.M. Whitman, V.S.Y. Lin. Nano Lett. 4 (2004) 2139-2143.

30. J. Yang, J. Lee, J. Kang, K. Lee, J.-S. Suh, H.-G. Yoon, Y.-M. Huh, S. Haam. Langmuir 24 (2008) 3417-3421.

31. T. Zhang, J. Ge, Y. Hu, Q. Zhang, S. Aloni, Y. Yin. Angew. Chem. 47 (2008) 5806-5811.

32. I. Tissot, J.P. Reymond, F. Lefebvre, E. Bourgeat-Lami. Chem. Mater. 14 (2002) 1325-1331.

33. L.I.C. Sandberg, T. Gao, B.P. Jelle, A. Gustavsen. Adv. Mater. Sci. Eng. 6 (2013) 483651.

34. C. Graf, D.L.J. Vossen, A. Imhof, A. van Blaaderen. Langmuir 19 (2003) 6693-6700.

35. L.M. Fortes, Y. Li, R. Réfega, M.C. Gonçalves. Opt. Mater. 34 (2012) 1440-1446.

36. M.C. Gonçalves, L.M. Fortes, M.B. Martins, A.D. Carvalho, G. Feio PCT/PT2014/000054 Multifunctional Superparamagnetic Nanosystem as Contrast Agent for Magnetic Resonance Imaging and Its Production Method (2014).

37. D. Escors, K. Brecpot. Arch. Immunol. Ther. Exp. 58 (2010) 107-119.

38. Gene Therapy Clinical Trials Worldwide Database, http://www.abedia.com/wiley/ (January 2015).

39. D.M.F. Prazeres, G.A. Monteiro. Plasmid Biopharmaceuticals 2(6) (2014) 616.

40. T. Murakami, Y. Sunada. Curr. Gene Ther. 11 (2011) 447-456.

41. W.M. Bertling, M. Gareis, V. Paspaleeva, A. Zimmer, J. Kreuter, E. Nürnberg, P. Harrer. Biotechnol. Appl. Biochem. 13 (1991) 390-405.

42. D. Luo, W.M. Saltzman. Nature biotechnol. 18 (2000) 33-37.

43. W.Li, F.C. Szoka. Pharm. Res. 24 (2007) 438-449.

44. A. del Pozo-Rodríguez, S. Pujals, D. Delgado, M.A. Solinís, A.R. Gascón, E. Giralt, J.L. Pedraz. J. Control. Release 133 (2009) 52-59.

45. S.D. Li, L. Huang. J. Control. Release 123 (2007) 181-183.

46. D.W. Pack, A.S. Hoffman, S. Pun, P.S. Stayton. Nature Rev. 4 (2005) 581-593.

47. T.M. Allen, P.R. Cullis. Science 303 (2004) 1818-1822.

48. S.C. Ribeiro, G.A. Monteiro, D.M.F. Prazeres. J. Gene Med. 6 (2004) 565-573.

49. A.R. Azzoni, S.C. Ribeiro, G.A. Monteiro, D.M.F. Prazeres. J. Gene Med. 9 (2007) 392-402.

50. H. Pollard, G. Toumaniantz, J.L. Amos, H. Avet-Loiseau, G. Guihard, J.P. Behr, D. Escande. J. Gene Med. 3 (2001) 153-164. 
51. D. Lew, S.E. Parker, T. Latimer, A.M. Abai, A. Kuwahara-Rundell, S.G. Doh, Z.Y. Yang, D. Laface, S.H. Gromkowski, G.J. Nabel. Human Gene Ther. 6 (1995) 553-564.

52. D.J.Bharali, I. Klejbor, E.K. Stachowiak, P. Dutta, I. Roy, N. Kaur, E.J. Bergey, P.N. Prasad, M.K. Stachowiak. Proc. Natl. Acad. Sci. U. S. A. 102 (2005) 11539-11544.

53. I. Roy, T.Y. Ohulchanskyy, D.J. Bharali, H.E. Pudavar, R.A. Mistretta, N. Kaur, P.N. Prasad. Proc. Natl. Acad. Sci. U. S. A. 102 (2005) 279-284.

54. S. Gan, P. Yang, W. Yang. Biomacromolecules 10 (2009) 1238-1243.

55. T. Liu, S. Wang, G. Chen. Talanta 77 (2009)1767-1773.

56. L.-S. Jang, H.-J. Liu. Biomed. Microdevices 11 (2009) 331-338.

57. T.-Y. Cheang, B. Tang, A.-W. Xu, G.-Q. Chang, Z.-J. Hu, W.-L. He, Z.-H. Xing, J.-B. Xu, M. Wang, S.-M. Wang. Int. J. Nanomedicine 7 (2012) 10617.

58. I. Roy, M.K.Stachowiak, E.J.Bergey. Nanomedicine 4 (2008) 89-97.

59. C. Kneuer, M. Sameti, U. Bakowsky, T. Schiestel, H. Schirra, H. Schmidt, C.M. Lehr. Bioconjugate Chem. 11 (2000) 926-932.

60. M. Yamazaki, T. Ito. Biochemistry 29 (1990) 1309-1314.

61. L.T. Boni, J.S. Hah, S.W. Hui, P. Mukherjee, J.T. Ho, C.Y. Jung. Biochim. Biophys. Acta 775 (1984) 409-418. 


\section{Chapter 9}

